\title{
Effect of Crumb Rubber as Coarse and Fine Aggregates on the Properties of Asphalt Concrete
}

\author{
${ }^{1}$ Arabi N.S. Al Qadi, ${ }^{1}$ Mahmoud B.A. Alhasanat and ${ }^{2}$ Madhar Haddad \\ ${ }^{I}$ Department of Civil Engineering, AL Hussein Bin Talal University, Ma'an, Box 20, Jordan \\ ${ }^{2}$ Department of Architectural Engineering, The United Arab Emirates (UAE) University, Al Ain, UAE
}

\author{
Article history \\ Received: 11-05-2016 \\ Revised: 17-06-2016 \\ Accepted: 23-06-2016 \\ Corresponding Author: \\ Arabi N.S. Al Qadi \\ Department of Civil \\ Engineering, AL Hussein Bin \\ Talal University, Ma'an, Box \\ 20, Jordan \\ Email: arabi@ahu.edu.jo
}

\begin{abstract}
This research has used crumb rubber in asphalt mixture as a part of the coarse and fine aggregate. Three sieve sizes of crumb rubbers were used in asphalt mixture No. 4, No. 8 and No. 50, with five percent of asphalt cements $(4,4.5,5,5.5$ and $6 \%)$ by weight and four percent of crumb rubbers $(10,20,30$ and $40 \%)$ by weight used as an aggregate for preparing asphalt mixture specimens. The Hot Mix Asphalt (HMA) Marshal test method for asphalt mixture specimens was used; 72 specimens were prepared for evaluation of Marshall Properties (flow, Stability, bulk density, air void percentage and void in mineral aggregate). Previous studies showed that the crumb rubber has further effects on the performance of asphalt mixture by increasing its Marshall flow, stability, air voids and decreasing the bulk density. It is concluded that the crumb rubber as a fine aggregate improves the stability and flow with respect to a crumb rubber as a coarse aggregate.
\end{abstract}

Keywords: Crumb Rubber, Fine and Coarse Aggregate, Asphalt Mixture, Marshall Test

\section{Introduction}

Transport Engineering is an application of scientific principles and technology in the planning, design, operation and management of transportation facilities in a manner that is safe, fast, convenient, easy, economical and environmentally friendly to transport people and goods. It is a major branch of civil engineering that is divided into four major sections: Roads engineering, trains engineering, airports engineering, ports and waterways engineering.

Crumb rubber in cold mixtures based on the idea of maximizing the valorization of recycled materials together was developed by Pettinari and Simone (2015). Two dissimilar gradations of crumb rubber have been approved for the production of a cold recycled mixture stabilized with bitumen and cement. The Indirect Tensile Stiffness and the Indirect Tensile Strength Modulus have been investigated. It was concluded that the gradation of the approved crumb rubber wisely affects the compaction and mechanical properties of the mixture.

Shu and Huang (2014) reviewed the use of waste tire rubber in Portland cement and asphalt. The rubberized asphalt mixtures have shown good compatibility with two widely used sustainability technologies in the asphalt paving industry; Warm-Mix Asphalt (WMA) and Reclaimed Asphalt Pavement (RAP).

Dondi et al. (2014) developed methods for the reuse of road bituminous materials. The study involves the use of crumb rubber within a mixture containing 100\% Reclaimed Asphalt Pavement (RAP) cold-recycled with bitumen emulsion and cement. Two dissimilar crumb rubbers were approved: One produced by the ambient production method and the other from the cryogenic process.

Presti (2013) viewed the technology as successful based on the evidence demonstrated by roads built in the last 40 years with the rubberized asphalt mixture obtained through the so-called "wet process" which involves the utilization of the Recycled Tire Rubber Modified Bitumen's (RTR-MBs). Since the 1960s, asphalt mixtures produced with RTR-MBs have been used in different parts of the world as solutions for different quality problems and, despite some downsides, in the majority of the cases, they were demonstrated to enhance the performance of road pavement. It was reported in a literature review on the existing technologies and specifications related to the production, handling and storage of RTR-MBs and on 
their current applications within road asphalt mixtures. In addition, considering RTR-MBs, technologies are still struggling to be fully adopted worldwide, mainly because of poor information, lack of training of personnel and stakeholders and largely unfavorable local policies. The present work aims to be an up-todate reference to clarify benefits and issues associated with this family of technologies and to provide suggestions for their widespread use.

Cao (2007) studied and tested the dry process of three types of asphalt mixtures containing various quantities of crumb rubber content $(0,1,2$ and $3 \%$ by weight of total mix). Founded on results of rutting tests at $60^{\circ} \mathrm{C}$, indirect tensile tests at $-10^{\circ} \mathrm{C}$ and difference analysis, the cold process of recycled tire rubber in asphalt mixtures enhance the properties of asphalt mixtures and the addition of the rubber has an important effect on performance in terms of resistance to lasting deformation at high temperature and cracking at low temperature.

Navarro and Gámez (2012) studied the effect of rubber on stiffness modulus and indirect tensile strength of hot asphalt mixes. They showed their study of the combination of rubber (by the dry process and the wet process) and its influence on the bearing capacity and cohesion of asphalt mixes. The results gotten show that rubber increased the stability and stiffness of mixes while, it somewhat reduced their indirect tensile strength. They concluded that adding crumb rubber to bituminous mixes enhances the lasting performance of road surfaces because it decreases the effect of traffic loads on the pavement.

Mashaan et al. (2013) evaluated crumb rubber and Stone Mastic Asphalt (SMA) pavements in Malaysia to prevent pavement distress and modified them through various solutions such as adopting new mix designs or utilization of asphalt additives. The aim of the study was to investigate the effect of adding crumb tire rubber as an additive to SMA mixture performance properties. Virgin bitumen of 80:100 penetration grade was used, modified with Crumb Rubber (CRM) at different modification levels of $6,12,16$ and $20 \%$ by the weight of the bitumen. The appropriate amount of the added CRM was found to be $12 \%$ by weight of bitumen.

Russell et al. (2011) proposed and used modified crumb rubber. Adding the crumb rubber to asphalt enhance the durability, cracking resistance, permanent deformation and reduce susceptibility to temperature. By varying the concentration of crumb rubber, a range of asphalt rubber mixtures with different performance characteristics can be made. The addition of $2 \%$ crumb rubber produces a more ductile, flexible and crack resistant material while the addition of $5 \%$ crumb rubber to TLA produces a more elastic material with higher resistance to deformation.
Zhao and Zhao (2014) studied the noise reduction and the surface performance of rubber micro-surfacing material; micro-surfacing is more widely used to protect the asphalt pavement for its superiority in China. Their study examined the influences of the rubber on the micro-surfacing material. The surface performance of the micro-surfacing mixture was exemplified and the noise reduction mechanism was investigated in the laboratory. It was concluded that the addition of the crumb rubber can significantly enhance the vibratory action between micro-surfacing pavement and the vehicle.

Cetin (2013) studied the effects of crumb rubber size and concentration on the performance of porous asphalt mixtures; the purpose of the research was to investigate the effect of size distribution and concentration of crumb rubber on the performance characteristics of porous asphalt mixture. The recycling of scrap tires in asphalt pavements appears to be an important alternative with a large market. The characteristics of bitumen are very important with regard to the service life of porous asphalt pavements. The experimental study consists of two main steps. First, the mixture design was performed to determine the optimum bitumen content. In the latter step, the mixtures were modified by the dry process using crumb rubber in three different grain size distributions of \#4 \#20, \#20 \#200 and \#4 \#200 and rubber content of 10,15 and $20 \%$ as the weight of optimum bitumen. Test results show that \#20 \#200 sized rubber particles reduced air voids and coefficient of permeability while they increased the Cantabro abrasion loss. It was concluded that increasing the crumb rubber size and content decreased the performance characteristics of the porous asphalt mixtures.

The objectives of this research are to study the process of adding the consumed tire rubber pieces to the asphalt cement mix and the effects of adding rubber to the mix by doing some tests on the rubberized asphalt mix and to compare the properties of the mixture before and after addition of rubber as a coarse and fine aggregate.

\section{Materials and Methods}

The methodology involves the selection of the asphalt content and the percentage of rubber, which satisfies some property values (stability, range of flow, density, air void, VMA) according to many tests and some equations.

\section{Aggregate}

One type of aggregate brought from the Ma'an quarries in Jordan was used in the study. Gradation was according to the Ministry of Public Works and Housing (MPWH) specification in Jordan. Table 1-A and D show the aggregate properties and gradation. 
Table 1. A, B, C and D. properties of the material used

\begin{tabular}{|c|c|c|c|c|}
\hline \multicolumn{5}{|c|}{ A. Aggregate Properties Used in Research } \\
\hline $\begin{array}{l}\text { Aggregate type } \\
\text { (Limestone) }\end{array}$ & $\begin{array}{l}\text { ASTM test } \\
\text { designation }\end{array}$ & $\begin{array}{l}\text { Bulk specific } \\
\text { gravity }\end{array}$ & $\begin{array}{l}\text { Apparent specific } \\
\text { gravity }\end{array}$ & $\begin{array}{l}\text { Absorption } \\
(\%)\end{array}$ \\
\hline Coarse agg. & $\mathrm{C} 127$ & 2.442 & 2.660 & 3.2 \\
\hline Fine agg. & $\mathrm{C} 128$ & 2.432 & 2.681 & 3.7 \\
\hline Mineral Filler & $\mathrm{C} 128$ & 2.497 & 2.682 & 3 \\
\hline \multicolumn{5}{|l|}{ B. Physical Properties of Asphalt } \\
\hline Test & Methods & Results & & \\
\hline Ductility, $25^{\circ} \mathrm{C}, \mathrm{cm}$ & ASTM D 113 & 100 & & \\
\hline Penetration, $25^{\circ} \mathrm{C}, 100 \mathrm{~g}, 5 \mathrm{~s}, 0.1 \mathrm{~mm}$ & ASTM D 5 & $80-100$ & & \\
\hline Softening point, ${ }^{\circ} \mathrm{C}$ & ASTM D 36 & 46 & & \\
\hline Flash point (Cleveland Open Cup), & ASTM D 92 & 260 & & \\
\hline${ }^{\circ} \mathrm{C}$, Fire Point, ${ }^{\circ} \mathrm{C}$ & & 310 & & \\
\hline Specific gravity, $25^{\circ} \mathrm{C}$ & ASTM D 70 & 1.013 & & \\
\hline \multicolumn{5}{|l|}{ C. Properties of Crumb Rubber } \\
\hline Properties & ASTM designation & Test result & & \\
\hline Specific gravity & & 1.15 & & \\
\hline Color & & Black & & \\
\hline \multicolumn{5}{|l|}{ D. Aggregate Gradation Used } \\
\hline $\begin{array}{l}\text { Sieve Size } \\
\text { (Midpoint) }\end{array}$ & \multicolumn{2}{|c|}{ Specification limits*(\% Passing) } & \multicolumn{2}{|l|}{$\%$ Passing } \\
\hline $1 "(25 \mathrm{~mm})$ & 100 & & 100 & \\
\hline 3/4" (19 mm) & $90-100$ & & 95 & \\
\hline $1 / 2 "(12.5 \mathrm{~mm})$ & $71-90$ & & 80.5 & \\
\hline $3 / 8^{\prime \prime}(9.5 \mathrm{~mm})$ & $56-80$ & & 68 & \\
\hline No. $4(4.75 \mathrm{~mm})$ & $35-56$ & & 45.5 & \\
\hline No. $8(2.35 \mathrm{~mm})$ & $23-38$ & & 30.5 & \\
\hline No. $20(850 \mu \mathrm{m})$ & $13-27$ & & 20 & \\
\hline No. $50(300 \mu \mathrm{m})$ & $5-17$ & & 11 & \\
\hline No. $80(180 \mu \mathrm{m})$ & $4-14$ & & 9 & \\
\hline No. $200(75 \mu \mathrm{m})$ & $2-8$ & & 5 & \\
\hline
\end{tabular}

*Ministry of Public Works and Housing (MPWH), Specification Sec. 4.01, Table 4.1 Wearing Mix (18)

\section{Asphalt}

The asphalt was obtained from the Jordan Petroleum Refinery Company. One penetration grade of asphalt cement (80:100) was used in this research. Table 1-B summarizes the physical properties of the asphalt used in the research.

\section{Crumb Rubber}

Crumb rubber was taken from the Advanced Technical Recycling Material Co., Ltd. Zarqa, Jordan. Crumb rubbers was used in the hot mix asphalt have $100 \%$ of the particles smaller than $4.75 \mathrm{~mm}$. While most of the particles used in the wet process are larger than $0.42 \mathrm{~mm}$, some crumb rubber particles may be as fine as $0.075 \mathrm{~mm}$. The specific gravity of crumb rubber is 1.15 and it was free of wire, fabric or other contaminants.

\section{Preparation of Rubber Aggregate}

The process of obtaining crumb tire includes cutting the outer part of the frame into small slices by a sharp knife and then washing them with water and drying them with air. The crumbs of tires were prepared by being crushed and ground into small pieces and then sieved to the sizes required. After doing a sieve test of the crumbs of tire, we selected the weight of tire retained on sieve [No. $4(4.75 \mathrm{~mm})$, No. 8 (2.36) $\mathrm{mm}$ and No. $50(300 \mu)]$.

\section{Preparation of Marshall Test}

Marshall mix design procedure (ASTM D1559) was the guide to find the best asphalt content by weight of total mix. Three samples at each asphalt content (4.0, $4.5,5.0,5.5$ and $6 \%$ ) were tested for air voids, flow, stability, voids in mineral aggregate and unit weight. The optimum asphalt content, which was the average of the asphalt contents that meet maximum unit weight, optimum stability and $4 \%$ air voids, was determined. The value of the optimum asphalt content was found to be $4.73 \%$ by weight of asphalt concrete mixture.

\section{Determination of Optimum Asphalt Content for Conventional Mixes}

The procedure followed in this study is indicated by the standard American Institute MS-2 Manual and the ASTM D1559. The aggregate must be washed, dried and sieved according to MPWH specifications. A $1200 \mathrm{gm}$ 
of aggregate was taken for Marshall specimen. The aggregate was heated to $149^{\circ} \mathrm{C}$ for $24 \mathrm{~h}$. Molds were heated to $149^{\circ} \mathrm{C}$ for $24 \mathrm{~h}$. The asphalt was heated to $149^{\circ} \mathrm{C}$ for only one hour. The hot asphalt and hot aggregate were mixed until full coating was achieved. The mixture was then placed in a Marshall mold. Each sample was compacted 50 blows on each face to represent medium traffic. Three specimens at each asphalt content $(4.0,4.5,5.0,5.5$ and $6 \%)$ of the weight of the mix were prepared. After $24 \mathrm{~h}$ the samples were extruded from the Marshall molds. The unit weight of each specimen was determined. Hot samples were submerged in water at $60^{\circ} \mathrm{C}$ for $40 \mathrm{~min}$ before testing. Samples were tested via Marshall Apparatus to determine flow and stability values. Table $1 \mathrm{~A}$ to $\mathrm{D}$ show the values of the tests.

\section{Results}

The results of all the tests that were made on the asphalt and aggregates and Marshall test results show the optimum asphalt content and the best rubber ratio which approved all the characteristics of the Marshall and gave the best combination of specifications. It includes Marshall sketches of all samples as shown in Table 2 and 3.

Figure 1-4 below show the Marshall property curves for the specimens without rubber. As demonstrated in Fig. 1, the optimum asphalt content without rubber is $6 \%$. This ratio is obtained based on Air void, curve at $\mathrm{AV}=4 \%$, intersect with curve to obtain asphalt content, then check (VMA, flow, stability) at this asphalt content if its values are within the range specification in the region of the study.

For Check (VMA, flow, stability) at this asphalt content, if its values are within the range specification in the region of the study, which follows these specification ranges: Marshall stability (Kg): 1000 (min) Marshall flow, mm: 2.0- 3.5 VMA (\%) : 14 (min) AV (\%): 4-6 At AC $=6 \%$ VMA is between (80$100)$; so it is within the ranges of VMA specifications $(\min 1000 \mathrm{Kg}), \mathrm{AV}=2 \%$; so it is within the ranges of AV specifications (4-6) and the control results as mentioned in Fig. 1 and Table 2 show that Optimum Asphalt Content (O.A.C.) $=4.72 \%$.

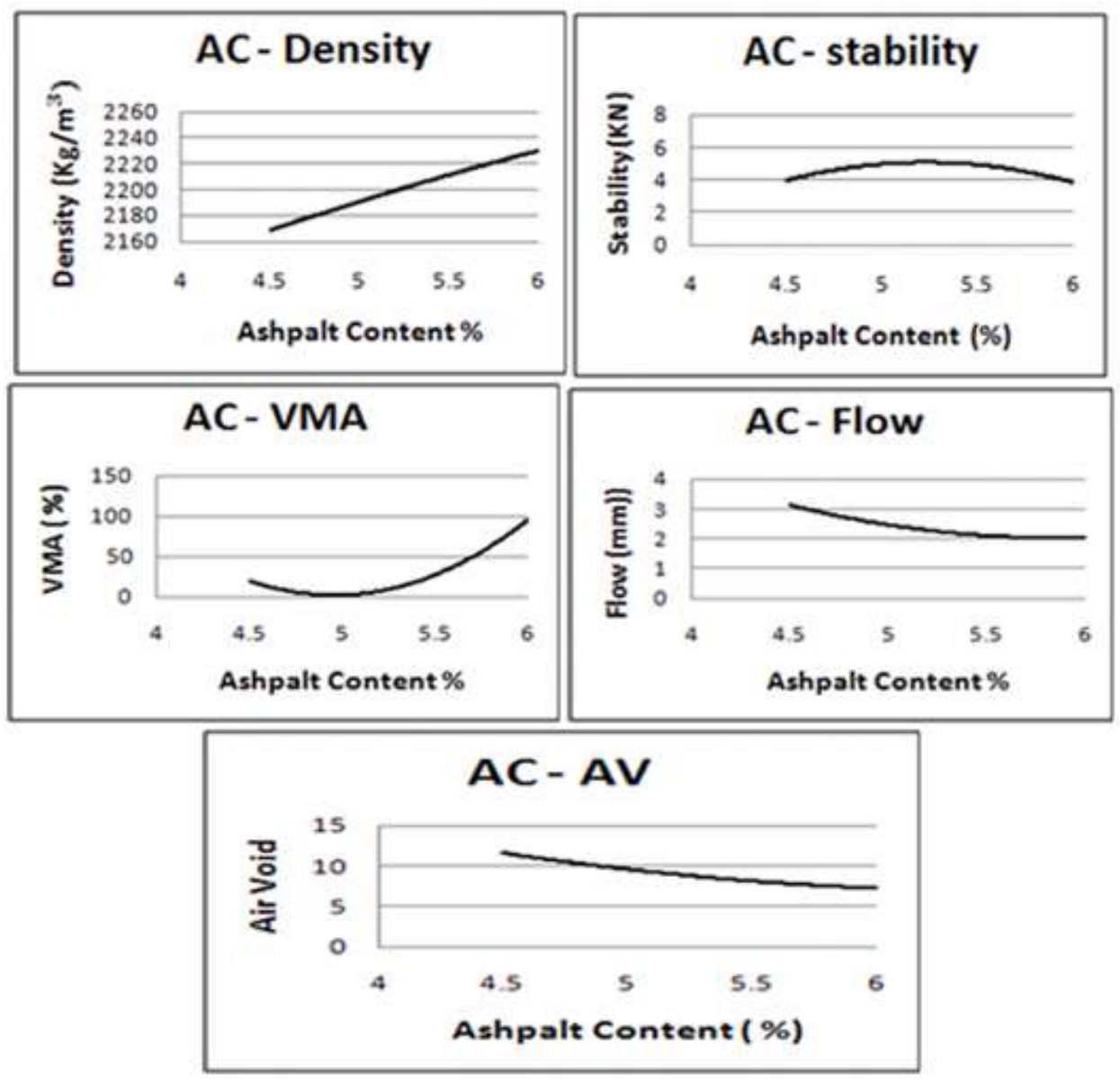

Fig. 1. Marshall property curves of samples without rubber 

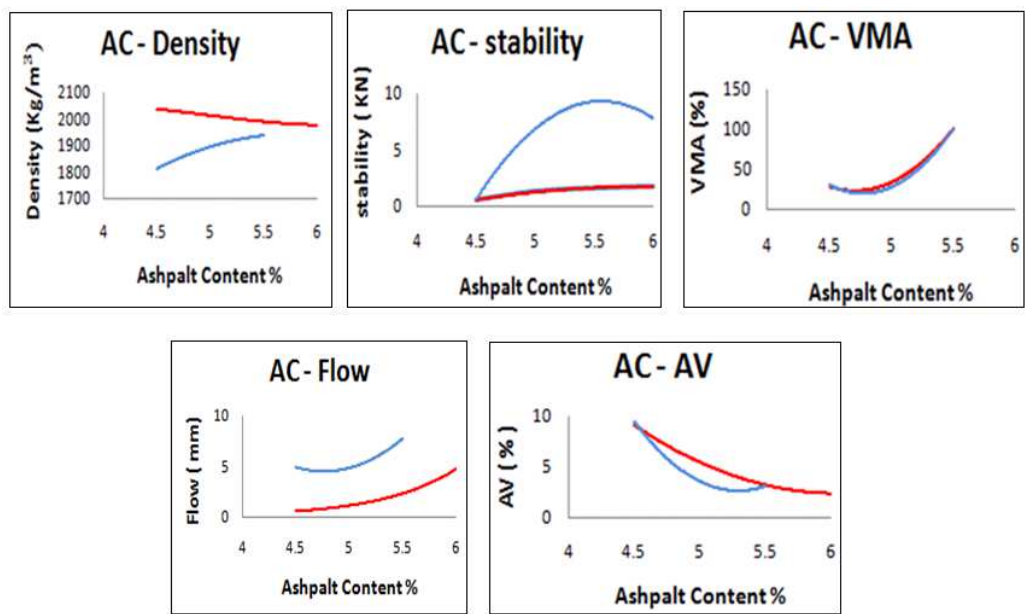

Fig. 2. Marshall property curve, blue for fine and red for coarse aggregate of samples with $20 \%$ rubber
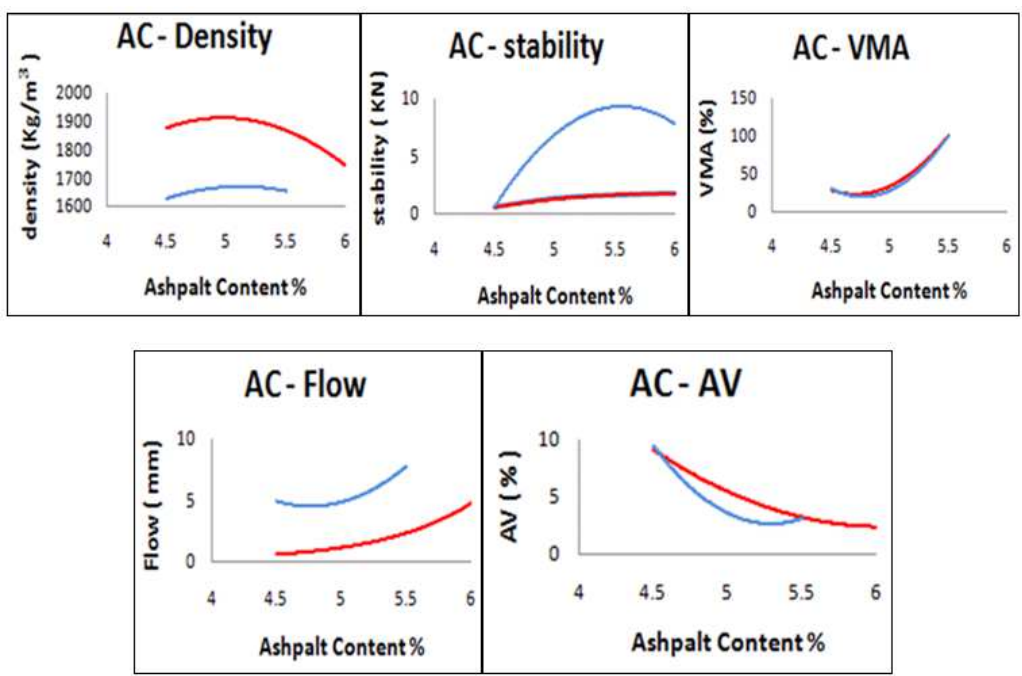

Fig. 3. Marshall Property curve, blue for fine and red for coarse aggregate of samples with $30 \%$ rubber
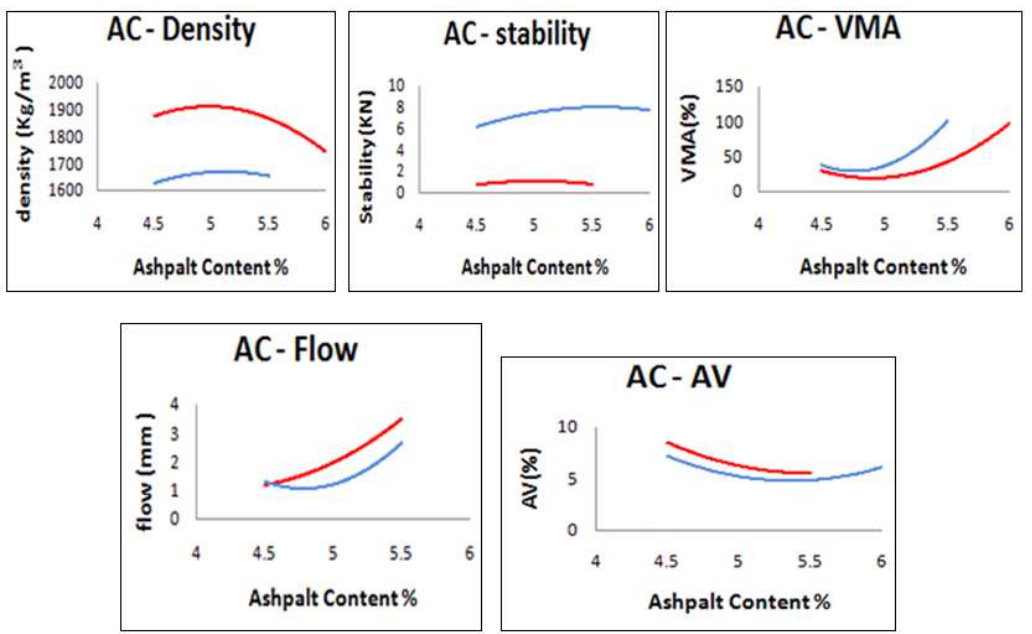

Fig. 4. Marshall Property curve, blue for fine and red for coarse aggregate of samples with $40 \%$ rubber 
Table 2. Result of Marshall test in determination of asphalt content without Rubber

\begin{tabular}{lllllll}
\hline Flow mm & Stab. KN & Gmm & VMA (\%) & AV (\%) & Theoretical max S.G & AC (\%) \\
\hline 4 & 2 & 2.450 & 15.33 & 11.423 & 2.45 & 4.0 \\
3 & 4 & 2.421 & 15.44 & 9.993 & 2,421 & 4.5 \\
2.5 & 5 & 2.392 & 15.05 & 7.697 & 2.392 & 5.0 \\
2 & 4.5 & 2.415 & 14.35 & 7.370 & 2.415 & 5.5 \\
2 & 4 & 2.430 & 99.99 & 4.000 & 2.403 & 6.0 \\
\hline
\end{tabular}

Table 3. Result of Marshall test in determination of asphalt content with rubber as a part of coarse and fine aggregate.

\begin{tabular}{|c|c|c|c|c|c|c|c|c|c|c|c|c|}
\hline \multicolumn{5}{|c|}{ Crumb rubber as fine aggregate } & \multicolumn{6}{|c|}{ Crumb rubber as coarse aggregate } & \multirow[b]{2}{*}{$\begin{array}{l}\text { Rub. } \\
\%\end{array}$} & \multirow[b]{2}{*}{$\mathrm{AC} \%$} \\
\hline $\begin{array}{l}\text { Flow } \\
\mathrm{mm}\end{array}$ & $\begin{array}{l}\text { Stab. } \\
\text { KN }\end{array}$ & $\mathrm{Gmm}$ & $\begin{array}{l}\text { VMA } \\
(\%)\end{array}$ & $\begin{array}{l}\text { AV } \\
(\%)\end{array}$ & $\begin{array}{l}\text { Flow } \\
\mathrm{mm}\end{array}$ & $\begin{array}{l}\text { Stab } \\
\text { KN }\end{array}$ & $\mathrm{Gmm}$ & $\begin{array}{l}\text { VMA } \\
(\%)\end{array}$ & $\begin{array}{l}\text { AV } \\
(\%)\end{array}$ & $\begin{array}{l}\text { Theo. Max } \\
\text { S.G }\end{array}$ & & \\
\hline 5.5 & 1.0 & 1.900 & 29.77 & 5.26 & 1.0 & 0.0 & 2.23 & 8.69 & 26.80 & 2.23 & 20 & 4 \\
\hline 0.5 & 1.0 & 1.820 & 34.49 & 7.74 & 0.5 & 0.5 & 2.09 & 9.62 & 26.30 & 2.09 & 30 & \\
\hline 1.5 & 5.0 & 1.745 & 36.56 & 6.81 & 1.5 & 1.0 & 2.05 & 8.49 & 26.80 & 2.05 & 40 & \\
\hline 5.0 & 1.5 & 1.956 & 29.98 & 7.77 & 1.5 & 1.0 & 2.15 & 6.51 & 24.47 & 2.15 & 20 & 4.5 \\
\hline 1.0 & 1.5 & 1.800 & 34.81 & 5.83 & 1.0 & 1.0 & 2.10 & 7.33 & 26.10 & 2.10 & 30 & \\
\hline 1.7 & 6.0 & 1.705 & 37.90 & 6.15 & 1.7 & 1.0 & 2.03 & 6.21 & 26.10 & 2.03 & 40 & \\
\hline 4.0 & 5.0 & 2.000 & 30.08 & 9.45 & 2.5 & 1.5 & 2.03 & 2.06 & 27.76 & 2.03 & 20 & $5 \%$ \\
\hline 1.5 & 2.0 & 1.846 & 31.43 & 3.79 & 1.0 & 7.0 & 2.02 & 6.44 & 27.06 & 2.02 & 30 & \\
\hline 1.0 & 8.0 & 1.690 & 37.26 & 3.84 & 2.0 & 2.0 & 1.98 & 5.51 & 27.76 & 1.98 & 40 & \\
\hline 6.0 & 9.0 & 1.963 & 27.26 & 3.51 & 3.0 & 1.5 & 2.03 & 2.71 & 33.21 & 2.03 & 20 & $5.5 \%$ \\
\hline 2.0 & 3.0 & 1.821 & 34.29 & 6.04 & 2.5 & 9.0 & 1.99 & 4.08 & 26.87 & 1.99 & 30 & \\
\hline 2.0 & 8.5 & 1.780 & 36.01 & 6.40 & 3.5 & 1.0 & 1.83 & 4.97 & 33.23 & 1.83 & 40 & \\
\hline 7.0 & 7.0 & 1.998 & 99.99 & 3.10 & 4.0 & 1.5 & 2.28 & 12.68 & 99.99 & 2.28 & 20 & $6 \%$ \\
\hline 4.0 & 2.0 & 1.920 & 99.99 & 7.34 & 3.0 & 6.0 & 1.94 & 2.73 & 99.99 & 1.94 & 30 & \\
\hline 3.0 & 7.0 & 1.682 & 99.99 & 1.84 & 4.0 & 1.5 & 1.96 & 3.62 & 99.99 & 1.96 & 40 & \\
\hline
\end{tabular}

\section{Discussion}

At each rubber percentage, the same procedure was repeated to obtain the O.A.C. after that selection of the best rubber ratio which agrees within regions of specifications. It is seen that at $\mathrm{AV}=4 \%$, Rubber $=30 \%$, from the intersection of Fig. 3, the $\mathrm{AC}=4.72 \%$ for samples with rubber as a part of the fine aggregate and $\mathrm{AC}=5.5 \%$ for samples with rubber as a part of the coarse aggregate. Check the (VMA, stability, flow) on this. In addition, asphalt content percentage of VMA with $(4.72 \%, 5.5 \%)$ gives: For sample with rubber as a part of fine aggregate: VMA $=(20-40) \%$; for sample with rubber as a part of coarse aggregate: VMA $=(40-$ $60) \%$, stability with $(4.72 \%, 5.5 \%)$ gives: For sample with rubber as a part of fine aggregate: Stability $=(6-8)$ $\mathrm{KN}$ with rubber as a part of coarse aggregate: Stability $=$ $(0.47-2) \mathrm{KN}$ and Flow with $(4.72 \%, 5.5 \%)$ gives: For the sample with rubber as a part of fine aggregate: Flow $=$ (2-4) $\mathrm{mm}$, for the sample with rubber as a part of coarse aggregate: Flow $=(3-4) \mathrm{mm}$. Repeat intersection steps based on AV curve for (20-40)\% rubber to find the best percentage of rubber and asphalt content for rubberized samples. At $\mathrm{AV}=4 \%$ for all rubberized samples, the intersection result gives the following readings: At $20 \%$ rubber as a part of fine aggregate $\mathrm{AC}=5.5 \%$ : flow $=(4-$ 6) $\mathrm{mm}$, stability $=(7.76) \mathrm{KN}, \mathrm{VMA}=(80-100) \%$, for sample with rubber as a part of coarse aggregate $\mathrm{AC}=$
4.75\%: Flow $=(2) \mathrm{mm}$, stability $=(0.49-1.25) \mathrm{N}, \mathrm{VMA}$ $=(20-40) \%$, the best rubber ratio is $30 \%$, for samples with rubber as a part of fine aggregate. The control results (as mentioned in Table 2 and 3 show that O.A.C. $=5.5 \%$ and the best rubber ratio is $30 \%$ for samples with rubber as a part of the coarse aggregate.

Figure 4 shows the Marshall property curves for specimens with $40 \%$ with rubber as a part of coarse aggregate and fine aggregate at $40 \%$ rubber as a part of fine aggregate $\mathrm{AC}=5.35 \%$, flow $=(1-2) \mathrm{mm}$, stability $=$ (6-8) $\mathrm{KN}$, VMA $=(20-40) \%$, with rubber as a part of coarse aggregate $\mathrm{AC}=6 \%$ : Flow $=(4.31) \mathrm{mm}$, stability $=(0-2) \mathrm{KN}, \mathrm{VMA}=(80-100) \%$.

\section{Conclusion}

The following conclusions were cited for this research:

- After conducting all previous tests, the final results show that O.A.C. $=4.72 \%$ with rubber $=30 \%$ for rubberized samples as a part of the fine aggregate. O.A.C. $=5.5 \%$ with rubber $=30 \%$ for rubberized samples as a part of coarse aggregate

- As to all air void curves for rubberized samples, note that the air voids in rubberized samples as a part of coarse aggregate are greater than air voids in rubberized samples as a part of fine aggregate; 
that is related to the larger size of rubber which is added instead of coarse aggregate, leading to more voids in samples

- $\quad$ Stability readings in final results are (6-8) $\mathrm{KN}$ as a fine rubber, (0.47-2) $\mathrm{KN}$ as a coarse rubber in both readings

- In general, all property of samples with rubber as a part of fine aggregate are better than samples with rubber as a part of the coarse aggregate

\section{Acknowledgement}

The authors would like to acknowledge Engineers Ahmad Abu-Syam, Aseel Al Dayyat, Baha'a Al Balawneh, Bra'ah Al Ghananeem and Hussein Al Sarayra for their help in carrying out this research.

\section{Author's Contributions}

Arabi N.S. Al Qadi: Participated in all experiments and discussion and contributed to the writing of this manuscript.

Mahmoud B. A. Alhasanat: Participated in all experiments and data analyses and contributed to the writing of this manuscript.

Madhar Haddad: Contributed to the writing of this manuscript.

\section{Ethics}

This article is original and contains unpublished material. The corresponding author confirms that all of the other authors have read and approved the manuscript and no ethical issues are involved.

\section{References}

Cao, W., 2007. Study on properties of recycled tire rubber modified asphalt mixtures using dry process. Constr. Build. Mater., 21: 1011-1015. DOI: 10.1016/j.conbuildmat.2006.02.004

Cetin, A., 2013. Effects of crumb rubber size and concentration on performance of porous asphalt mixtures. Int. J. Polymer Sci., 2013: 789612-789621. DOI: $10.1155 / 2013 / 789612$
Dondi, G., P. Tataranni, M. Pettinari, C. Sangiorgi and A. Simone et al., 2014. Crumb Rubber in cold recycled bituminous mixes: Comparison between traditional crumb rubber and cryogenic crumb rubber. Constr. Build. Mater., 68: 370-375. DOI: $10.1016 /$ j.conbuildmat.2014.06.093

Mashaan, N.S., A.H. Ali, S. Koting and M.R. Karim, 2013. Performance evaluation of crumb rubber modified stone mastic asphalt pavement in Malaysia. Adv. Mater. Sci. Eng., 2013: 304676-304683. DOI: $10.1155 / 2013 / 304676$

MPWH, 1991. Highway and bridge construction. Ministry of Public Works and Housing Directorate of Planning and Development Specification.

Navarro, F. and M. Gámez, 2012. Influence of crumb rubber on the indirect tensile strength and stiffness modulus of hot bituminous mixes. J. Mater. Civil Eng., 24: 715-724.

DOI: 10.1061/(ASCE)MT.1943-5533.0000436

Pettinari, M. and A. Simone, 2015. Effect of crumb rubber gradation on a rubberized cold recycled mixture for road pavements. Mater. Design, 85: 598-606. DOI: 10.1016/j.matdes.2015.06.139

Presti, D.L., 2013. Recycled tyre rubber modified bitumens for road asphalt mixtures: A literature review. Constr. Build. Mater., 49: 863-881. DOI: 10.1016/j.conbuildmat.2013.09.007

Russell, S.N., R. Maharaj and A.S. George, 2011. Endof-life management of scrap tyres using crumb rubber modified TLA. Int. J. Applied Environ. Sci., 6: 91-102.

Shu, X. and B. Huang, 2014. Recycling of waste tire rubber in asphalt and portland cement concrete: An overview. Constr. Build. Mater., 67: 217-224.

DOI: 10.1016/j.conbuildmat.2013.11.027

Zhao, M.L. and Z.L. Zhao, 2014. Study on noise reduction mechanism and surface performance of crumb rubber micro-surfacing material. Key Eng. Mater., 599: 257-260.

DOI: 10.4028/www.scientific.net/KEM.599.257 